\title{
Continental roots go with the flow
}

Walter D. Mooney

ON page 50 of this issue, Vinnik et al. ${ }^{1}$ add fresh fuel to a heated geological debate. The question is whether the continents have deep, stable roots that have remained practically unchanged since the Precambrian era, or whether plate motion in geologically recent times has deformed those roots. Vinnik et al., working with seismic anisotropy measurements in the Kaapvaal craton of South Africa, have evidence that the continental root has been sheared by the flow of the underlying mantle. Dating back to the Archaean, 2.5 billion years ago, the Kaapvaal is one of the oldest of the Earth's cratons (regions of crust that have remained almost undisturbed for millions of years).

Seismologists continue to discover uses for late-arriving seismic phases in defining the properties of the Earth's interior. In just the past decade or so, work has progressed beyond refining models of the seismic velocity distribution of the Earth using global seismic tomography. In the process, an important discovery was made: the subcontinental mantle shows seismic anisotropy parallel to the Earth's surface ${ }^{2-4}$. This is evidenced by shear-wave splitting, where an incident wave is polarized into two orthogonal directions travelling at different velocities (the phenomenon is analogous to birefringence in minerals).

Seismic anisotropy of the mantle is generally taken to arise from strain-induced preferred orientation of highly anisotropic crystals such as olivine. In the oceanic lithosphere, for instance, seafloor spreading aligns mantle olivine crystals with their seismically 'fast' direction perpendicular to the spreading ridge ${ }^{5}$. The challenge has been to work out how, when and where, within the supposedly stable continents, this alignment could have arisen.

Shear-wave splitting, and hence anisotropy within the continental mantle, can be quantified by examining the seismic phase SKS, which travels through the liquid outer core of the Earth as a compressional $(\mathrm{P})$ wave and emerges at the base of the mantle as a shear (S) wave. This phase travels nearly vertically through the mantle, and any shear-wave splitting depends on the magnitude and depth of anisotropy in the subcontinental mantle.

There's the rub. As the SKS phase vertically integrates seismic anisotropy from the base of the mantle to the detector on the surface (a distance of $2,885 \mathrm{~km}$ ), the depth extent of the anisotropy is ambiguous. It could arise from a near-surface mineral alignment or from deep in the mantle. There has been a gradual consensus that the anisotropy is concentrated in the upper mantle, as the measured azimuth of anisotropy sometimes changes by as much as $90^{\circ}$ at seismic stations separated by only hundreds of kilometres. As SKS phases recorded $100 \mathrm{~km}$ apart would have practically the same path in the lower mantle, the anisotropy must be within the upper mantle, that is, above the main mantle discontinuity at a depth of $660 \mathrm{~km}$.

To narrow the range down further, Vinnik et al. add the observation that the

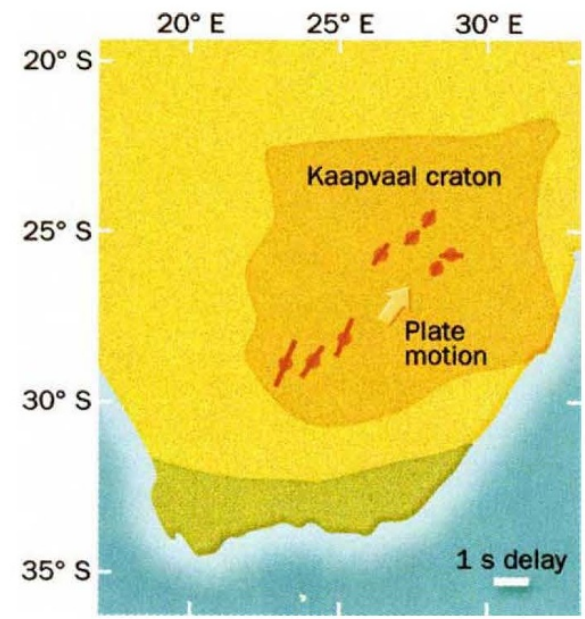

Anisotropy in the Kaapvaal craton ${ }^{1}$ : lines show polarization direction of the fast wave. Their lengths indicate the time lag of the slow wave.

mobility of olivine is temperature-dependent and will be significant only at temperatures over $1,000{ }^{\circ} \mathrm{C}$, corresponding to depths greater than $150 \mathrm{~km}$ beneath stable cratons. Combining this with mineralogical arguments ${ }^{6}$ for decreasing intrinsic anisotropy below $400 \mathrm{~km}$, Vinnik et al. conclude that mantle anisotropy is localized between 150 and $400 \mathrm{~km}$ deep (that is, within the supposedly stable lithospheric 'root' of the Precambrian continent). This depth range is more limited than earlier estimates that only localized mantle anisotropy between 40 and $670 \mathrm{~km}$, with little consensus about where exactly it occurred.

So far so good, but Vinnik et al. were looking at the dual question of the depth extent and origin of the anisotropy. Even if most of the anisotropy arises in the upper mantle, it is uncertain whether it dates back to the Precambrian assembly of the continents more than 600 million years ago or is a recent feature caused by deformation of the root as the continental plates drift.

Vinnik et al. find that in measurements taken at eight seismic stations deployed across the Kaapvaal craton of South Africa, the azimuth of the seismic anisotropy is closely aligned with the direction of absolute plate motion for southern Africa since the end of the Jurassic period. So they reject the earlier notion ${ }^{4}$ that seismic anisotropy is primarily a fossil feature of the lithosphere, and argue that it is the result of resistive drag by the mantle. Something similar has been seen elsewhere: the alignment reported for the North American craton ${ }^{3}$ (by a group again led by Vinnik) is also in the direction of current continental drift.

The Precambrian continental lithosphere was assembled from microplates that collided and coalesced into stable cratonic blocks, much as the large continental plates of India and Eurasia have recently collided. The earlier hypothesis that mantle seismic anisotropy is a fossil feature dating back to the assembly of Precambrian lithosphere ${ }^{4}$ was based on sparser data than the new South African data reported here by Vinnik and coworkers. In the assessment of Vinnik et $a l$., fossil anisotropy in the South African lithosphere should have been indicated by anisotropy that was everywhere parallel to the azimuth of microplate assembly of the Kaapvaal craton. Their observation that, instead, the azimuth of anisotropy is uniformly aligned with the direction of absolute plate motion makes a mobilistic interpretation more likely to be correct.

Nonetheless, there is little doubt that the fossil deformation model could be applied to the observations in this paper by a sufficiently skilful writer. In other words, although the interpretation offered here is appealing (and very likely correct), it is not the only one possible.

To distinguish between the rival models for the origin of mantle anisotropy, detailed measurements will be needed from the remaining Precambrian cratons elsewhere in Africa and the other continents. Then we should be able to see whether the azimuth of seismic anisotropy is nearly always parallel to the current plate motion, or nearly always parallel to the direction of the original microplate accretion. For now, though, the 'mobilistic' interpretation seems to have overtaken the 'fossil' viewpoint.

Walter D. Mooney is in the United States Geological Survey, 345 Middlefield Road, MS 977, Menlo Park, California 94925, USA.

\footnotetext{
1. Vinnik, L. P., Green, R. W. E. \& Nicolaysen, L. O. Nature 375, 50-52 (1995)

2. Vinnik, L. P., Kosarev, G. L. \& Makeyeva, L. I. Dokl. Akad. Nauk USSR 278, 1335-1339 (1984).

3. Vinnik, L. P., Makeyeva, L. I., Milev, A. \& Usenko, A. Yu. Geophys. J. int. 111, 433-447 (1992).

Silver, P. G. \& Chan, W. W. Nature 335, 34-39 (1988)

5. Raitt, R. W., Shor, G. G., Francis, T. J. G. \& Morris, G. B. J. geophys. Res. 74, 3095-3109 (1969).

6. Mainprice, D. \& Silver, P. G. Phys. Earth planet. Inter 78, 207-227 (1993).
} 